\title{
Ocorrência de bactérias do grupo do Bacillus cereus em leite UHT integral (Ultra-High-Temperature)
}

\section{Occurrence of Bacillus cereus microorganisms group in integral UHT (Ultra High Temperature) milk}

\author{
Naiá Carla Marchi de Rezende, ${ }^{*}$ Oswaldo Durival Rossi Júnior, ${ }^{\star *}$ Luiz Augusto do Amaral**
}

\begin{abstract}
Resumo
Foram analisadas 120 amostras de leite UHT ("ultra-high-temperature") integral, de quatro diferentes marcas comerciais (A, B, $C$ e D), adquiridas no comércio da região de Ribeirão Preto/SP, para verificar-se a presença e a contagem de bactérias do grupo do Bacillus cereus (B. cereus, $B$. mycoides, $B$. anthracis e B. thuringiensis) no produto recém-adquirido e após o mesmo permanecer por 48 horas sob refrigeração (amostras refrigeradas). O Bacillus cereus esteve presente em $17(14,2 \%)$ amos-

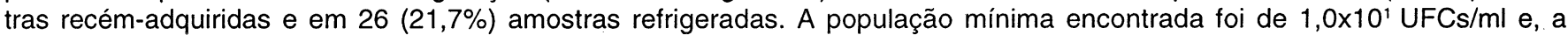
máxima, de $3,8 \times 10^{4}$ UFCs $/ \mathrm{ml}$.
\end{abstract}

Palavras-chave: Bacillus cereus, leite UHT.

\begin{abstract}
A total of 120 UHT (ultra-high-temperature) integral milk samples of 4 differents commercial brands, purchased form Ribeirão Preto-SP region, were analysed for the presence and number of Bacillus cereus microorganisms group (Bacillus cereus, $B$. mycoides, B. anthracis e Bacillus thuringiensis) in newly purchased samples and after the samples were stored for 48 hours in refrigerator. Bacillus cereus microorganisms group occurred in $17(14,2 \%)$ newly purchased samples and in $26(21,7 \%)$ cold samples. The leavel of Bacillus cereus microorganisms group varied from $1,0 \times 10^{1} \mathrm{UFCs} / \mathrm{ml}$ to $3,8 \times 10^{4} \mathrm{UFCs} / \mathrm{ml}$.
\end{abstract}

Keywords: Bacillus cereus; UHT milk.

\section{Introdução}

As toxiinfecções de origem alimentar são tidas como doenças adquiridas através da ingestão de alimentos contaminados por determinados microrganismos ou por suas toxinas. Inúmeros estudos demonstram que os principais fatores responsáveis por surtos de toxiinfecções alimentares são a falta de higiene com que os alimentos são obtidos e/ou processados, o acondicionamento e conservação inadequados de alimentos prontos ou semiprontos e o processamento térmico insuficiente destes produtos.

Os microrganismos mais comumente incriminados em surtos de toxiinfecções alimentares são Salmonella spp., Escherichia coli, Staphylococcus aureus, Clostridium perfringens e bactérias do grupo do Bacillus cereus (Bacillus cereus, $B$. anthracis, $B$. mycoides e $B$. thuringiensis). Dentre estes microrganismos, destacam-se aqueles pertencentes ao grupo do Bacillus cereus.

As bactérias do grupo do Bacillus cereus estão assim reunidas por possuírem uma grande similaridade cromossomal entre si, o que resulta em uma grande semelhança genotípica e fenotípica, sendo difícil a diferenciação das quatro espécies
(Ash et al., 1991; Drobniewski, 1993). De acordo com Stadhouders (1992a), dada a alta homologia do DNA, as quatro diferentes espécies do grupo do Bacillus cereus poderiam ser classificadas como uma única espécie.

Por estar muito difundido no meio ambiente, o Bacillus cereus encontra-se presente em muitos alimentos (Stadhouders, 1992b). Não é incomum a contaminação de leite e derivados, carne e derivados, diferentes produtos em pó, arroz, óleos, condimentos, farináceos e alimentos infantis por diferentes cepas de Bacillus cereus que, encontrando condições satisfatórias, podem provocar toxiinfecção alimentar nos consumidores destes produtos (Becker e Terplan, 1993; Griffiths, 1993; Becker et al., 1994; Crielly et al., 1994; Little e Knochel, 1994; Lee et al., 1995). A habilidade de seus esporos de sobreviver por longos períodos em alimentos desidratados e a sua resistência térmica ajudam a explicar a grande variedade de alimentos contaminados com o Bacillus cereus e que podem causar surtos de toxiinfecções (Johnson, 1984; Sallam et al., 1991).

Além de causar toxiinfecções de origem alimentar, o Bacillus cereus também é responsável pela degradação de vários produtos alimentícios, particularmente leite e cremes (Rusul e Yaakob, 1995).

\footnotetext{
* Pós-graduanda do Curso de Medicina Veterinária, Área de Concentração Medicina Veterinária Preventiva, FCAVJ-UNESP.

** Departamento de Medicina Veterinária Preventiva, FCAVJ-UNESP, Rodovia Carlos Tonanni Km 5, CEP 14870-000 - Jaboticabal, SP, Brasil.
} 
Atualmente, a alta do consumo do leite longa vida pela população brasileira vem ocorrendo em progressão geométrica. Segundo Souza (1976) e Ferrini (1977), as suas vantagens incluem economia de frio e equipamentos para tal, facilidades de comercialização e preço competitivo, sendo muitas vezes menor do que o do leite pasteurizado.

A legislação brasileira que regulamenta a produção de leite UHT estabelece que o produto não deve ter microrganismos capazes de proliferar em condições normais de armazenamento e distribuição, pelo que após a incubação da embalagem fechada a $35-37^{\circ} \mathrm{C}$ durante sete dias, nenhuma amostra de cinco analisadas de uma mesma partida pode conter mais do que 100 microrganismos mesófilos $/ \mathrm{ml}$ de leite (Brasil, 1996). Essa legislação é complementada por uma portaria que descreve que alimentos UHT estáveis à temperatura ambiente e comercialmente estéreis, após 10 dias incubados a $35^{\circ} \mathrm{C}$, não devem apresentar sinais de alteração da embalagem nem quaisquer modificações físicas, químicas e organolépticas do produto que evidenciem deterioração (Brasil, 1997).

São poucos os trabalhos que relatam a ocorrência do Bacillus cereus em leite longa vida (UHT). Rangasamy et al. (1993) analisaram amostras de leite e derivados para a presença do Bacillus cereus, incluindo amostras de leite UHT. Do total de amostras analisadas, $26,4 \%$ foram positivas para a presença do Bacillus cereus, embora o leite UHT tenha sido o único produto a não apresentar o microrganismo pesquisado. Shoken-Iturrino et al. (1996) analisaram amostras de leite longa vida e encontraram aproximadamente $25 \%$ delas contaminadas com Bacillus spp.

Tendo em vista o apresentado, idealizou-se o presente trabaIho, cujo objetivo é verificar a presença de microrganismos do grupo do Bacillus cereus em leite UHT, através da determinação de esporos e de células vegetativas do referido microrganismo.

\section{Material e métodos}

Foram analisadas 120 amostras de leite longa vida (UHT) integral de quatro diferentes marcas comerciais, representadas pelas letras $A, B, C$ e $D$, sendo 30 amostras de cada marca.

As amostras foram adquiridas no comércio de Ribeirão Preto (SP) e região e analisadas no laboratório de microbiologia de alimentos do Departamento de Medicina Veterinária Preventiva da Faculdade de Ciências Agrárias e Veterinárias de Jaboticabal - UNESP.

As análises relativas à pesquisa e contagem de células vegetativas e esporos de bactérias do grupo do Bacillus cereus foram realizadas no momento em que as embalagens eram abertas e repetidas após 48 horas de permanência das mesmas sob refrigeração.

Pesquisa de células vegetativas e/ou esporos de bactérias do grupo do Bacillus cereus: para tal, inicialmente foi realizado o enriquecimento seletivo, onde 10 mililitros de cada amostra foram transferidos para um frasco esterilizado tipo Erlenmeyer contendo 90 mililitros de caldo soja triptona (TSB) adicionado de polimixina $B$ na proporção de $20 \mathrm{~mm} / \mathrm{ml}$ (Stadhouders, 1992b). Após incubação a $30^{\circ} \mathrm{C}$ por 24-30 horas, foi realizado o plaqueamento seletivo em ágar manitol-gema de ovo vermelho de fenol polimixina $B$ (MYP), segundo recomenda Mossel et al. (1967). As placas foram incubadas a $30^{\circ} \mathrm{C}$ por 18 a 40 horas e, ao final deste período, três a cinco unidades formadoras de colônias (UFCs) sugestivas das espécies do grupo do Bacillus cereus, ou seja, aquelas que se apresentavam róseas, de aspecto rugoso e seco, medindo entre 3 e 6 milímetros de diâmetro, rodeadas por um halo esbranquiçado formado pela ação da lecitinase (Mossel et al., 1967), foram repicadas em tubos contendo ágar soja triptona (TSA) inclinado, devidamente identificado. Após a incubação $\left(30^{\circ} \mathrm{C} / 24\right.$ horas), foram preparados esfregaços para a coloração de Gram e de WirtzConklin (Bier, 1975). Uma vez constatada a presença de bastonetes Gram positivos com esporo centro-terminal, foram realizadas provas bioquímicas (catalase, motilidade, redução de nitrato a nitrito, reação de Voges-Proskauer, fermentação anaeróbia da glicose, hemólise em sangue de carneiro e crescimento rizóide) para confirmação das UFCs como pertencentes ao grupo do Bacillus cereus (Harmon et al., 1992).

Contagem de células vegetativas e/ou esporos de bactérias do grupo do Bacillus cereus: nesta determinação, 0,1 mililitro de cada amostra de leite UHT foi inoculado na superfície do ágar MYP. Após realizar incubação por 18 a 40 horas a $30^{\circ} \mathrm{C}$, as UFCs sugestivas do grupo foram contadas e submetidas às provas bioquímicas para confirmação.

Pesquisa de esporos de bactérias do grupo do Bacillus cereus: após a realização de choque térmico $\left(80^{\circ} \mathrm{C} / 10 \mathrm{minu}\right.$ tos com posterior refrigeração), procedeu-se o enriquecimento seletivo com posterior plaqueamento, conforme já descrito anteriormente.

Contagem de esporos de bactérias do grupo do Bacillus cereus: realizou-se o mesmo procedimento já descrito, sendo que as amostras, antes de serem semeadas na superfície do ágar MYP, foram submetidas ao choque térmico, nas condições pré-citadas.

\section{Resultados e discussão}

Como pode ser observado na Tabela 1, das 120 amostras de leite UHT analisadas no momento da sua abertura ( $\mathrm{h}$ ), nove $(7,5 \%)$ foram positivas para a presença de microrganismos do grupo do Bacillus cereus, sendo quatro $(3,3 \%)$ positivas para células vegetativas e/ou esporos $(\mathrm{CV}+\mathrm{E})$ e cinco $(4,2 \%)$ para a presença apenas de esporos (amostras submetidas a choque térmico). Após a permanência sob refrigeração (48 horas), houve isolamento dos microrganismos de grupo do Bacillus cereus em $18(15,0 \%)$ e seis $(5,0 \%)$ amostras, respectivamente, para células vegetativas ou esporos $(C V+E)$ e apenas para esporos (E), totalizando $24(20,0 \%)$ amostras positivas. Pode-se verificar um aumento significativo $(p<0,05)$ no total de amostras positivas nos dois momentos da análise ( 0 e 48 horas). 
Tabela 1: Número de amostras de leite UHT de 4 diferentes marcas comerciais, adquiridas na região de Ribeirão Preto-SP, analisadas para a presença de células vegetativas e/ou esporos $(C V+E)$ e apenas de esporos (E) de bactérias de grupo do $B$. cereus, antes e após a permanência por 48 horas sob refrigeração

\begin{tabular}{|c|c|c|c|c|c|c|c|}
\hline \multirow[t]{2}{*}{ Marcas } & \multirow{2}{*}{$\begin{array}{l}\mathrm{N}^{2} \text { amostras } \\
\text { analisadas }\end{array}$} & \multicolumn{3}{|c|}{$\mathrm{N}^{\circ}$ amostras positivas - Oh } & \multicolumn{3}{|c|}{$\mathrm{N}^{0}$ amostras positivas - $48 \mathrm{~h}$} \\
\hline & & $(C V+E)^{1}$ & $(E)^{2}$ & Total & $(C V+E)$ & $(E)$ & Total \\
\hline A & 30 & $1(3,3)$ & $1(3,3)$ & $2(6,7)$ & $2(6,7)$ & $1(3,3)$ & $3(10,0)$ \\
\hline B & 30 & $3(10,0)$ & $3(10,0)$ & $6(20,0)$ & $5(16,7)$ & $1(3,3)$ & $6(10,0)$ \\
\hline c & 30 & $\cdot$ & $1(3,3)$ & $1(3,3)$ & $4(13,3)$ & $1(3,3)$ & $5(19,7)$ \\
\hline D & 30 & - & $\cdot$ & - & $7(23,3)$ & $3(10,0)$ & $10(33,3)$ \\
\hline Total & 120 & $4(3,3)$ & $5(4,2)$ & $9(7,5)$ & $18(15,0)$ & $6(5,0)$ & $24(20,0)$ \\
\hline
\end{tabular}

${ }^{1}$ Número de amostras positivas para a presença de células vegetativas e/ou esporos de bactérias do grupo do $B$. cereus.

${ }^{2}$ Número de amostras positivas para a presença de esporos de bactérias do grupo do $B$. cereus (amostras que sofreram choque térmico).

Os dados demonstrados na Tabela 2 apontam as populações absolutas e médias encontradas nas amostras de leite UHT analisadas. Neste caso, em cinco $(4,2 \%)$ amostras foi possível realizar a contagem de células vegetativas e/ou esporos no momento da abertura da embalagem, com população variando de $1,0 \times 10^{1}$ a $3,8 \times 10^{4} \mathrm{UFCS} / \mathrm{ml}$ (média de $1,6 \times 10^{2}$ UFCs $/ \mathrm{ml}$ ) para as três amostras positivas da marca $A$ e de 1,0 a $2,0 \times 10^{1}$ (média de $1,4 \times 10^{1} \mathrm{UFCs} / \mathrm{ml}$ ) para as duas amostras positivas da marca B. Logo após a abertura da embalagem, quatro $(3,3 \%)$ amostras apresentaram-se positivas para esporos de bactérias do grupo do $B$. cereus, sendo uma amostra de cada marca comercial, com popula-

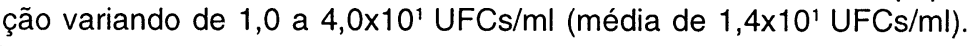

Ainda pela Tabela 2 , verifica-se que, após as amostras terem permanecido sob refrigeração, foi possível realizar a contagem de células vegetativas ou esporos de bactérias do grupo do $B$. cereus em cinco
$(4,2 \%)$ amostras, sendo quatro da marca $C$ e um da marca $D$. A população encontrada variou de $1,0 \times 10^{1}$ a $5,0 \times 10^{2}$ UFCs $/ \mathrm{ml}$, com média de $3,9 \times 10^{1} \mathrm{UFCs} / \mathrm{ml}$. Após as amostras terem sido submetidas a choque térmico, pode-se realizar a contagem de esporos em quatro $(3,3 \%)$ amostras, sendo uma da marca $A$ e três da marca $D$. Neste caso, a população encontrada foi a mesma em to-

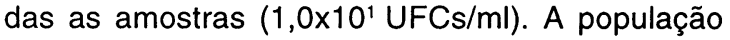
de esporos de bactérias do grupo do Bacillus cereus encontrada é, aparentemente, pequena. No entanto, salienta-se que, dependendo das condições em que o leite for armazenado, a germinação dos esporos pode ocorrer de forma rápida, seguindose a multiplicação das células vegetativas e o conseqüente aumento da população microbiana, fato que pode levar a casos de toxiinfecção alimentar.

De acordo com Becker et al. (1994), populações de $1,0 \times 10^{3} \mathrm{UFCs} / \mathrm{ml}$ são potencialmente capazes de causar toxiinfecção alimentar. Assim, pode-se dizer que a amostra da marca $A$, cuja população foi de $3,8 \times 10^{4}$ UFCs $/ \mathrm{ml}$, coloca em risco a saúde do consumidor. Vlaemynck \& Van Heddeghem (1992) citam que o tempo médio de geração de cepas de $B$. cereus isoladas de leite chega a 39 minutos a $31^{\circ} \mathrm{C}$. Mcknight et al. (1990) ressaltam que a avaliação do risco potencial de um alimento não deve limitar-se apenas ao estudo da sua contaminação inicial, mas também a uma estimativa da sua adequação para a multiplicação dos contaminantes.

No presente estudo, verificou-se a diminuição da população encontrada, semelhante ao achado por Dufrenne et al. (1994), que verificaram a diminuição do desenvolvimento das bactérias do grupo do $B$. cereus ao permanecerem sob refrigeração.

Tabela 2: Populações absolutas e médias de bactérias e esporos de bactérias do grupo do Bacillus cereus encontradas em 120 amostras de leite UHT de quatro diferentes marcas comerciais, adquiridas na região de Ribeirão Preto-SP, antes e após a permanência por 48 horas sob refrigeração

\begin{tabular}{|c|c|c|c|c|c|c|c|c|c|c|c|c|}
\hline \multirow[t]{4}{*}{ Marcas } & \multicolumn{12}{|c|}{ População encontrada } \\
\hline & \multicolumn{6}{|c|}{ Amostras recém-abertas (Oh) } & \multicolumn{6}{|c|}{ Amostras após refrigeração por 48 horas } \\
\hline & \multicolumn{3}{|c|}{$(C V+E)^{\prime}$} & \multicolumn{3}{|c|}{$(E)^{2}$} & \multicolumn{3}{|c|}{$(C V+E)^{1}$} & \multicolumn{3}{|c|}{$(E)^{2}$} \\
\hline & $\mathrm{N}^{0^{3}}$ & $\mathrm{PA}^{4}$ & $\mathrm{PM}^{5}$ & $\mathrm{~N}^{0^{3}}$ & $P A^{4}$ & $\mathrm{PM}^{5}$ & $\mathrm{~N}^{0^{3}}$ & $\mathrm{PA}^{4}$ & $\mathrm{PM}^{5}$ & $\mathrm{~N}^{0^{3}}$ & $P A^{4}$ & $\mathrm{PM}^{5}$ \\
\hline A & 3 & $\begin{array}{c}1,0 \times 10^{1} \\
a \\
3,8 \times 10^{4}\end{array}$ & $1,6 \times 10^{2}$ & 1 & $1,0 \times 10^{1}$ & $1,0 \times 10^{1}$ & - & - & - & 1 & $1,0 \times 10^{1}$ & $1,0 \times 10^{1}$ \\
\hline B & 2 & $\begin{array}{c}1,0 \times 10^{1} \\
a \\
2,0 \times 10^{1}\end{array}$ & $1,4 \times 10^{1}$ & 1 & $1,0 \times 10^{1}$ & $1,0 \times 10^{1}$ & - & - & - & $\cdot$ & - & $\cdot$ \\
\hline $\mathrm{C}$ & - & - & - & 1 & $4,0 \times 10^{1}$ & $4,0 \times 10^{1}$ & 4 & $\begin{array}{c}1,0 \times 10^{1} \mathrm{a} \\
5,0 \times 10^{2}\end{array}$ & $5,5 \times 10^{1}$ & $\cdot$ & - & $\cdot$ \\
\hline $\mathrm{D}$ & - & $\cdot$ & - & 1 & $1,0 \times 10^{1}$ & $1,0 \times 10^{1}$ & 1 & $1,0 \times 10^{1}$ & $1,0 \times 10^{1}$ & 3 & $1,0 \times 10^{1}$ & $1,0 \times 10^{1}$ \\
\hline Total & 5 & & $6,0 \times 10^{1}$ & 4 & & $1,4 \times 10^{1}$ & 5 & & $3,9 \times 10^{1}$ & 4 & & $1,0 \times 10^{1}$ \\
\hline
\end{tabular}

R. bras. Ci. Vet., v. 7, n. 3, p. 162-166, set./dez. 2000 
Com base nas informações apresentadas, pode-se afirmar que a inadequada armazenagem do leite pode transformá-lo, em curto espaço de tempo, num potencial agente causador de toxiinfecção pelo $B$. cereus, mesmo que a população inicial de microrganismos não seja relevante.

De forma geral, foram positivas $41(34,2 \%)$ amostras de leite UHT para a presença de microrganismos do grupo do $B$. cereus, independentemente do momento da análise. Os dados apresentados no presente trabalho são bastante relevantes, principalmente quando se observa o termo "leite esterilizado" em algumas embalagens de leite longa vida. Essa denominação não é verdadeira e, portanto, não deve ser utilizada.

Os resultados encontrados no presente estudo diferem daqueles descritos por Rangasamy et al. (1993), pois os autores, ao analisarem 10 amostras de leite UHT na Austrália, não encontraram nenhuma amostra contaminada com Bacillus cereus. Neste caso, verifica-se que o número de amostras analisadas foi bastante pequeno, o que dificulta qualquer conclusão. Por outro lado, Huh e Kim (1983) analisaram amostras de leite UHT de oito diferentes marcas comerciais, num total de 60 amostras. Destas, 14 (23,3\%) estavam contaminadas com Bacillus spp. Das 67 cepas isoladas, três foram identificadas como Bacillus cereus. Em trabaIho semelhante, Schocken-Iturrino et al. (1996) analisaram 32 amostras de leite longa vida colhidas na região de Ribeirão Preto (São Paulo, Brasil), encontrando 19 (59,37\%) amostras contaminadas com Bacillus spp. Os autores concluem que o tratamento térmico pode ser insuficiente para a destruição dos esporos e que a terminologia "estéril" não deve ser usada para o leite UHT.

De acordo com Bergère e Cerf (1992), o tratamento térmico denominado UHT é suficiente para reduzir a população de esporos de Bacillus cereus a um valor que não causa riscos à saúde pública. Assim, a presença de Bacillus cereus em leite longa vida pode ser atribuída, segundo os autores, à alta população de esporos no leite cru, à utilização de tratamento térmico insuficiente ou à contaminação pós-tratamento térmico.

\section{Referências bibliográficas}

ASH, C., FARROW, J.A.E., DORSCH, M., STACKEBRANDT, E., COLLINS, M.D. Comparative analysis of Bacillus anthracis, Bacillus cereus, and related species on the basis of reverse transcriptase sequencing of $16 \mathrm{~S}$ rRNA. Int. J. Syst. Bacteriol., Washington, v. 41, n. 3, p. 343-346, 1991.

BECKER, H. TERPLAN, G. Importance of Bacillus cereusin infant foods and powdered milk products. Bull. Int. Dairy Fed, Brussels, n. 287, p. 18-19, 1993.

BECKER, H., SCHALLER, G., WIESE, W. VON, TERPLAN, G. Bacillus cereus in infant foods and dried milk products. Int. J. Food Microbiol., Amsterdam, v. 23, n. 1, p. 1-15, 1994.

BERGÈRE, J.L., CERF, O.C. Heat resistance of Bacillus cereusspores. Bull. Int. Dairy Fed., Brussels, n. 275, p. 23-25, 1992.

BIER, O. Bacteriologia e Imunologia: em suas aplicações à medicina e à higiene. 16. ed. São Paulo: Melhoramentos, 1975. p. 842-843.

BRASIL. Portaria n. 146, 7 mar. 1996. Regulamentos técnicos de identidade e qualidade de produtos lácteos. Diário Oficial da União, Brasilia, DF, n. 48, p. 3.977-3.986, Seção 1.
Não pode ser esquecido que o consumidor imagina, ao optar pelo leite UHT, estar adquirindo um produto de boa qualidade microbiológica. No presente estudo, os resultados evidenciaram que essa qualidade, particularmente em relação ao grupo do Bacillus cereus, vai se degradando à medida que avança o tempo de conservação do leite, mesmo sob temperatura de refrigeração.

O presente trabalho deixa clara a necessidade de novos estudos para a determinação da presença de microrganismos anaeróbios no leite UHT, uma vez que sua embalagem forma um meio totalmente anaeróbio e comporta um produto rico em substratos para vários microrganismos, que permanece por um longo período à temperatura ambiente. Também sugere-se a determinação dos principais pontos de contaminação para o leite UHT durante o seu processamento, bem como as alterações que o tratamento térmico pode trazer aos microrganismos presentes no leite. Ainda destaca-se a necessidade de uma legislação clara e uma fiscalização rigorosa e eficiente quanto às características microbiológicas que o leite UHT deve apresentar para poder ser comercializado, uma vez que a população consumidora imagina estar consumindo um leite "estéril".

\section{Conclusões}

Nas condições em que o trabalho foi realizado, baseando-se no número de amostras analisadas e nos resultados obtidos, é possível concluir que: 1) o leite UHT recém-adquirido pode trazer riscos à saúde pública, uma vez que houve amostras positivas para esporos e células vegetativas dos microrganismos do grupo do Bacillus cereus, 2) a qualidade microbiológica do leite UHT se torna ainda mais comprometida à medida que aumenta o seu tempo de armazenagem, mesmo sob refrigeração, 3) a denominação de "leite esterilizado" não deve ser atribuída ao leite UHT, já que o mesmo não apresenta tal característica, e 4) a legislação interna deve rever seus padrões e elaborar normas mais claras e objetivas sobre as características microbiológicas do leite UHT destinado à população humana.

BRASIL. Portaria n. 451, 19 set. 1997. Regulamentos técnicos - Princípios gerais para o estabelecimento de critérios e padrões microbiológicos para alimentos. Diário Oficial da União, Brasília, DF, n. 182, p. 21.005-21.012, Seção 1.

CRIELLY, E.M., LOGAN, N.A., ANDERTON, A. Studies on the Bacillus flora of milk and milk products. J. Appl. Bacteriol., Oxford, v. 77, n. 3, p. 256-263, 1994.

DROBNIEWSKI, F.A. Bacillus cereus and related species. Clin. Microbiol. Rev., Washington, v. 6, n. 4, p. 324-338, 1993.

DUFRENNE, J., SOENTORO, P., TATINI, S., DAY, T. NOTERMANS, S. Characteristics of Bacillus cereus related to safe food production. Int. J. Food Microbiol., Amsterdam, v. 23, n. 1, p. 99-109, 1994.

FERRINI, C. Comercialização de produtos lácteos assépticos. Rev. Inst. Latic. Cândido Tostes, Juiz de Fora, v. 32, n. 189, p. 49-54, 1977.

GRIFFITHS, M.W. Bacillus cereus in liquid milk. Bull. Int. Dairy Fed., Brussels, n. 287, p. 18, 1993.

HARMON, S.M., GOEPFERT, J.M., BENNETT, R.W. Bacillus cereus. In: VANDERZART E SPLITTSTOESSER. Compendium of Methods for the Microbiological Examination of Foods. Washington, 1992. p. 593-604. 
HUH, C.S., KIM, H.U. A study on the mesophilic Bacillus species occurring in Korean market milk treated by ultra high temperature. Korean J. Dairy Sci., v. 15, n. 1, p. 29-36, 1983.

JOHNSON, K.M. Bacillus cereus foodborne illness - an update. J. Food Prot., Ames, v. 47, n. 2, p.145-153, 1984.

LEE, P.K., BUSWELL, J.A., SHINAGAWA, K. Technical report: distribuition of toxigenic Bacillus cereus in rice samples marketed in Hong Kong. World J. Microbiol. Biotech., v.11, n. 6, p. 696-698, 1995.

LITTLE, C.L., KNOCHEL, S. Growth and survival of Yersinia enterocolitica, Salmonella and Bacillus cereus in Brie stored at 4,8 and $20^{\circ} \mathrm{C}$. Int. J. Food Microbiol., Amsterdam, v. 24, n. 1-2, p. 137-145, 1994.

McKNIGHT, I.C.S., LEITÃO, M.F.F., LEITÃO, R.F.F. Bacillus cereus em macarrões industrializados. II. Ocorrência em produtos comerciais e sua multiplicação no alimento preparado para consumo. Rev. Microbiol., São Paulo, v. 21, n. 3, p. 268-275, 1990.

MOSSEL, D.A.A., KOOPMAN, M.J., JONGERIUS, E. Enumeration of Bacillus cereus in foods. Appl. Microbiol., Washington, v. 15, n. 3, p. 650-653, 1967.

RANGASAMY, P.N., IYER, M., ROGINSKI, H. Isolation and characterisation of Bacillus cereusin milk and dairy products manufactured in Victoria. Aust. J. Dairy Technol., Highett, v. 48, n. 2, p. 93-95, 1993.
RUSUL, G. YAACOB, N.H. Prevalence of Bacillus cereus in selected foods and detection of enterotoxin using TECRA-VIA and BCETRPLA. Int. J. Food Microbiol., Amsterdam, v. 25, n. 2, p.131-139, 1995.

SALLAM, S.S., HAFEZ, N.M., EL-KHOLY, A.M., AMER, I.H. Incidence of Bacillus cereus in milk and some dairy products in Egypt. J. Egyp. Vet. Med. Ass., Dar El Hekma, v. 51, n. 1-2, p. 153-159, 1991.

SCHOCKEN-ITURRINO, R.P., NADER FILHO, A., DIMENSTEIN, A.R. Ocorrência de bactérias esporuladas dos gêneros Bacillus e Clostridium em amostras de leite longa vida. Higiene Alimentar, v. 10, n. 42, p. 25-27, 1996.

SOUZA, G. Processamento de leite longa vida por temperatura ultraalta e breve tempo. Bol. Inst. Tecnol. Aliment., Campinas, n. 48, p.117-128, 1976.

STADHOUDERS, J. Taxonomy of Bacillus cereus. Bull. Int. Dairy Fed., Brussels, n. 275, p. 4-8, 1992a.

. The enumeration of spores and vegetative cells of $B$. cereus. Bull. Int. Dairy Fed., Brussels, n. 275, p. 15-18, 1992 b.

VLAEMYNCK, G., Van HEDDEGHEM, A. Factors affecting the growth of Bacillus cereus. Bull. Int. Dairy Fed., Brussels, n. 275, p. 26-29, 1992. 